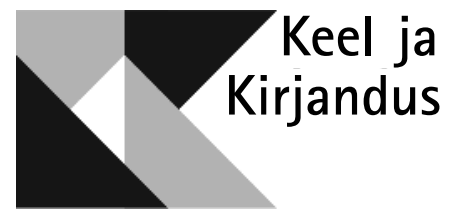

LVI AASTAKÄIK

EESTI TEADUSTE AKADEEMIA JA EESTI KIRJANIKE LIIDU AJAKIRI

\title{
KÄÄBUSTEST JA HIIGLASTEST
}

\author{
MEELIS FRIEDENTHAL
}

$\mathrm{D}$ okumentaalfilmis „Derrida”1 (2002) küsib ajakirjanik Amy Kofman filosoof Jacques Derrida raamatukokku astudes, kas too on lugenud kõiki neid raamatuid. Derrida vastab justkui teravmeelitsedes, et „sugugi mitte, ainult nelja”, kuid lisab pärast väikest järelemõtlemist: „Ent selle eest väga põhjalikult.” Selline sentiment lugemise suhtes ei ole mõistagi midagi uut. Inglise esseist Francis Osborne kirjutab XVII sajandi keskpaigas oma pojale nõuandeks, et too ei langeks üliagara lugemise ohvriks, sest „vähesed raamatud, mis on hästi läbi töötatud ja põhjalikult läbi seeditud, toidavad arusaamist paremini kui sajad, mida on vaid põgusalt mälutud" (vt Frasca-Spada, Jardine 2000: 302-303).

Põhimõtteliselt sedasama märgati juba varakeskajal: lugeda on võimalik rohkem kui ühel moel ning sellest tulenevalt täidavad erinevad lugemisviisid erinevaid eesmärke. On raamatuid, mida ei kõlbagi põhjalikult läbi töötama hakata, ja on selliseid, mille lugemisest pole mingitki kasu, kui neid põhjalikult läbi ei tööta. See aga ei tähendanud siis ega tähenda ka tänapäeval tingimata, et need lugemisviisid oleksid kuidagi hierarhilises suhtes, vaid kõige sagedamini eksisteerivad eri tüüpi lugemised kõrvuti, üksteist täiendades.

Lugemine on alati seotud väga otseselt raamatutehnoloogiatega. Seetõttu pole meie XXI sajandi alguse arengud, kus ennustatakse e-raamatute formaadi domineerimist paberraamatu üle ning kurdetakse Twitteri-kõnepruugi pärast, midagi uut võrreldes XV sajandiga, mil võeti kasutusele trükikunst. Ka siis leidus neid, kes tundsid, et uus trükitehnoloogia kuidagi vähendab kir-

\footnotetext{
${ }^{1}$ Kirby Dick, Amy Ziering Kofman, Derrida (dokumentaalfilm). Zeitgeist Films, 2002.
} 
jutamise ja lugemise väärtust, muutes seda hõlpsamini kättesaadavaks, ning seega odavamaks - nii otseses kui ka metafoorses tähenduses. Selle heaks näiteks on universaalõpetlase Johannes Trithemiuse De laude scriptorum manualium ehk „Käsitsi kirjutajate kiituseks”, mis ilmus 1494. aastal küll iroonilisel kombel trükisena. See oli muuhulgas üks esimesi raamatuid, mis hakkas tänapäevasega sarnasel kujul kasutama tiitellehte. Enne seda olid tiitellehed üldiselt üsna vähese informatsiooniga või sageli üldse puudusid. Teisisõnu, kiites käsitsi kirjutamist, tõi Trithemiuse tekst sisse olulisi uuendusi trükitud raamatute juures.

Kuigi näiteks George Steiner, kelle essee lugemise kohta ilmus eestikeelsena Loomingu Raamatukogus 2008. aastal (Steiner 2008), ei tsiteeri Trithemiust, võib teda paigutada kuulsa universaalõpetlasega samasse ritta. Samamoodi tajub ta, et on toimumas muutused, ning need muutused ei ole alati paremuse poole. Arvestades tema essee kirjutamise aega (1978), pole teemaks mitte e-raamatud, vaid odavad pehmekaanelised köited (paperback'id), mis aga sisuliselt kannavad sedasama tähendust. Steiner rõhutab, et pidulik ja omaette tõelises vaikuses ja keskendunud lugemine on tänapäeval erinevate tehnoloogiliste segajate tõttu kadumisele määratud. Veel kaugemale läheb saksa kirjanik ja esseist Thomas Hettche. Oma veidi moralistliku tooniga loos „Papüürused” (2012) väidab ta: „Käimas on hiiliv hääbumisprotsess, mida on tunda kõikjal: raamatukauplustes, ülikoolides, raadiojaamades, kirjandusmajades, koolides" (Hettche 2013: 811). Ta nimetab seda meediavahetuse ajajärguks ning on veendunud, et „mitte midagi ei jää alles” (Hettche 2013: 812) ja „Kaotsi ei lähe mitte raamat ise, vaid arusaam, et teksti piirab algus ja lõpp, niisiis arusaam totaalsusest, mille puhul oletatakse, et too on autori, üheainsa tuvastatava autori väljamõeldud ja teostatud...." (Hettche 2013: 816).

Leian, et apokalüptilisteks meeleoludeks ei ole siiski põhjust. Mille poolt siinkohal sõna võetakse, on tegelikult ju vaid üks võimalik - ja sugugi mitte kõige iidsem - lugemisviis. Steiner ja Hettche igatsevad siin taga sellist tüüpi lugemist, mida kirjeldab XVIII sajandi lõpus oma mitmesajaleheküljelises käsiraamatus tollal populaarne kirjamees Johann Adam Bergk. Soovituseks kirjutab ta, et lugedes peame arvestama erineva stiili ja temaatikaga autoreid, kuid pidama sealjuures silmas alati ka ümbritsevat keskkonda ja omaenda füsioloogiat: lugeda ei tohiks seetõttu kunagi seistes ega vahetult pärast sööki. Samuti tuleks eelnevalt pesta nägu külma veega, lahkuda kabinetist ja lugeda, viibides omaette looduses; lugeda oleks soovitav ka valjusti, et häälekõla aitaks kaasa vooruslike ideede täielikumale omaksvõtmisele. Kaasas peaks lugeja alati kandma sulge ning alla joonima kõik need kohad, mida ta märkimisväärseks peab. Neid omakorda oleks tarvis ikka ja jälle uuesti üle korrata (Bergk 1799: 406-410). See on töökas, plaanipärane, mingis mõttes weberlikult protestantliku vaimuga lugemisideaal ${ }^{2}$ ja sellisena väga kiiduväärt.

Lugemine keskajal ja antiigis oli aga küllalt erinev sellest, mida Steiner, Hettche ja Bergk kirjeldavad. See haaras endasse tegevusi alates ühislugemistest ja ettelugemistest kuni vaikse omaette lugemiseni välja (sellest on teateid juba varakult, nt V saj eKr Euripidese tragöödias „Hippolytos”). ${ }^{3}$ Antiigis oli

${ }^{2}$ Trükipressi ja reformatsiooni seostele on viidatud üsna sageli, nt Eisenstein 1980: $303 \mathrm{jj}$ ).

${ }^{3}$ Hilisantiigis ei olnud vaikselt lugemine siiski väga tavaline, nii et näiteks Augustinus pidas oluliseks oma „Pihtimustes” eraldi välja tuua, kui ta nägi Ambrosiust vaikselt lugemas (vt Augustinus, „Pihtimused”, 6.3). 
suurem osa teksti mõeldud siiski teistele esitamiseks (laulud, teater, dialoogid jms). Sokrates läks koguni nii kaugele, et pidas vestlust palju olulisemaks kui lugemist ja võrdles igasugust kirjutatud sõna meenutamise farmakoniga (ka unustamise rohuga; vt Platon, „Phaidros”, 274e-275b).

Antiiksed tekstid olid alati kirjutatud ilma sõnavahedeta ja minimaalse punktuatsiooniga, kuid see-eest struktureeritud eeldusega, et neid kuulatakse. Nii oli üldiselt kombeks esitada meetrilisi tekste ridades, kus reavahetus tähendas ka värsi lõppu, samuti oli lugemisel abiks sõnade loomulik rõhk ja värsimõõdu etteaimatavus ja korrapärasus. Vana-Rooma tekstid olid kirjutatud Egiptusest imporditud papüüruslehtedest kokkuliimitud rullraamatutesse, mida loeti üldjuhul avatud portikusel või aias valju häälega ette - kas iseendale või kuulajate grupile. Seetõttu oli lugemine pigem avalik tegevus. Sotsiaalne ja väljapoole suunatud tegevus polnud aga mitte ainult lugemine, vaid isegi kirjutamine. Raamatuid üldjuhul dikteeriti valju häälega kirjutajale, kes laused üles märkis, autorile ette luges ning viis sisse parandused, kuhu vaja. Teksti autor ei olnud niisiis oma tekstiga enamasti üksi. Teatavas mõttes sarnaneb hellenismiaegne lugemine tänapäevase sotsiaalmeediaga või wikitüüpi ettevõtmisega, kus tekstiloome on ühine. Sellele viitavad ka niisuguste tegevuste jaoks inglise keeles kasutusele võetud sõnad nagu forum ja scroll. On ju arvutiekraanilt lugemine sarnane pigem rullraamatu kui koodeksi teksti lugemisele.

Koodeksi formaadis raamat (nagu me seda tänapäeval ikka veel oleme harjunud nägema ja mida sageli tõstetakse esile kui raamatu ainuvõimalikku ja muutumatut vormi) võeti laiemalt kasutusele alles hilisantiigis, kristlikus keskkonnas. Üheks põhjuseks võis olla see, et nii eraldasid kristlased oma raamatud paganlikest tekstidest, mis olid kirjutatud rullraamatutesse. Teiseks on välja toodud, et Piiblisse suhtuti eelkõige kui praktiliseks kasutamiseks mõeldud teksti - sarnaselt vahatahvlitega, kuhu tavaliselt kirjutati märkmeid äriasjade kohta. Koodeksit on kergem lehitseda ja sealt vajalikku kohta üles leida, kirjutamiseks saab kasutada raamatulehe mõlemat poolt. Varakeskajal olid koodeksite lehed nii köitetehnoloogiat kui ka Egiptusega katkenud kaubandussidemeid arvesse võttes valmistatud juba pärgamendist, mis oli oluliselt vastupidavam (aga kallim) materjal kui habras papüürus. Raamatu formaadi muutumise tagajärjel muutus mõistagi ka see, kuidas neid loeti - kas või puhttehniliselt ei olnud koodeksit võimalik lugeda samamoodi kui rullraamatut. Enam ei olnud lugemine eelkõige sotsiaalne tegevus, vaid pigem meditatiivne, omaette teksti süvenemine ning isiklik kohtumine loetuga. Toimus ka uuendus kirjutamises: kasutusele tulid sõnavahed. Sõnade eraldamine oli antiigis ja ladina keelt emakeelena kõnelevatele inimestele tundmatu ning selle võtsid kasutusele iirlased millalgi VII sajandi paiku. Ilma sõnavahedeta lugemisel tuleb kas või mõttes ikkagi foneeme kombineerida, kuid alles vahede tekkega saab võimalikuks pilgul haarata tervet sõna korraga ning ei tekigi vajadust kõiki tähti välja lugeda. Enamasti loetaksegi nii, et tuntakse ära sõna, vahel isegi terve lauseosa korraga. ${ }^{4}$ Vaid lapsed veerivad aeglaselt tähti kokku, kiirustavale (aga mitte kuigi põhjalikule) lugejale piisab pilgust lõigule, kui ta võib juba selle mõtet aimata.

${ }^{4}$ Selline asjaolu on mureks toimetajatele: sageli jäävad sõnas vahetusse läinud tähed kahe silma vahele, sest olemuslik on õigete tähtede kohalolek, mitte nende järjekord. 
Mis aga veelgi olulisem - sõnavahede teke suurendas ka kirjutamise kiirust. Probleem seisneb nimelt selles, et ilma sõnavahedeta kirja pandud teksti ei saa autor hõlpsasti üle kontrollida, sest pilk ei haara lauseid ega suuda vajalikku kohta üles leida (Saenger 2003). Just seetõttu kirjutati antiigis enamasti dikteerimismeetodit kasutades, autor suhestus peale teksti alati veel ühe inimesega ning sellist intiimsust, millega seostatakse kirjutamist tänapäeval, üldiselt ei tuntud.

Alles XI sajandiks on sõnavahedega kirjutamise näiteid teada suuremast osast Euroopast ja XII sajandil suureneb niiviisi kirja pandud tekstide hulk märgatavalt. Seda uuendust mõjutas muidugi suuresti grammatikale pühendatud tekstidele iseloomulik esituslaad, sest just grammatikad eraldasid sõnu üksteisest, et lugeja saaks neid paremini identifitseerida. Niisiis hakkas sõnavahede ja punktuatsiooni tekkega VII sajandil Euroopas aeglaselt levima skolastiline ehk koolitraditsioon - kui mõista skolastikat kindlat tüüpi lugemisja kirjutamispraktikana. Sõnad muutusid korraga haaratavateks üksusteks, mida hakkasid rõhutama alates XII sajandist süsteemseks muutuvad lühendused sõnalõpul (us, um) kui ka lõpp-positsioonile iseloomulikud tähed (nt $s$ ). Samuti tekib autoril punktuatsiooni abil võimalus teksti lugejale just sellisel moel kättesaadavaks teha, nagu ta seda on plaaninud. XII sajandi õpetlane Salisbury Johannes on võrrelnud punktuatsiooni muusikaliste neumadega (keskaegsed noodikirjamärgid; Saenger 2003: 123). Just sel ajal hakkas tekstides esile kerkima ka autori „mina”, mis enne oli enamasti tagaplaanil (teatud erandid varasemast ajast muidugi olid, nagu Augustinus ja Boethius). Nii ongi XII sajandit peetud isiku avastamise sajandiks (nt Morris 2004) ning üheks peamiseks näiteks on toodud ajalookirjutaja Guitbertus de Novigento, kes muuhulgas on kurtnud selle pärast, et kui ta elu lõpupoole pimedaks jäi ja ise enam kirjutada ei suutnud, pidi ta kasutama sekretäri, suutes kirjutada „ainult mälust, ainult häälega, ilma käeta, ilma silmadeta" (Saenger 1997: 417). ${ }^{5}$ Tekst, mille varasemal ajal pani kirja enamasti vahendaja ning mis oli seega olemuslikult ebaisikuline, muutus nüüd isiklikumaks. Just keskajal tekkinud autori isiku kohalolekut peetakse sageli raamatu definitsiooni juures oluliseks (nagu Hettche ülal). Nüüd tekib nii autoril kui ka lugejal võimalus suhestuda tekstiga omaette olles, vahetult.

Selline suhe tekstiga tõi endaga kaasa ka raamatu lehekülje ümberkorralduse, peamise rõhuga visuaalsusel. Juba XI sajandiks oli küll tavaks saanud tekste rubritseerida (teatud sõnu punase tindiga esile tuua) ning varustada ääremärkustega, kuid XIII sajandiks muutus niisugune lehekülje ülesehitus peaaegu kohustuslikuks ning lisandusid veel tähistatud lõigud, kohati isegi foliatsioon (lehtede nummerdamine) ${ }^{6}$ ja lehekülje päised (Hexter, Townsend 2012: 159). Read jooniti ning tekst piirati kastiga, lehe ja tekstikasti suhe nihkus kuldlõikelisse proportsiooni (nn van de Graafi kaanon). Kõik need elemendid on mõeldud lugeja pilgu kiiremaks ja paremaks juhtimiseks, aga mitte ettelugemiseks. Näiteks suhestuvad pimedad, kellele teksti ette loetakse (nüüdsel ajal teeb seda sageli arvuti), loetuga teisel viisil kui nägijad - tänapäeva nägijad ei loe praegu enam kunagi nii aeglaselt. Peale selle on paljudele meist kas või ettekannete ja loengute kuulamisest selgeks saanud, et silmadega lugemiseks mõeldud tekst muutub valjusti ette lugedes kohmakaks ja isegi

\footnotetext{
${ }^{5}$ Sola memoria, sola voce, sine manu, sine oculis.

${ }^{6}$ Lehek ülge de nummerdamine (nagu tänapäeval paberraamatutes) on alles varauusaegne praktika.
} 
inetuks. Vastupidiselt jällegi - mõningad tekstid (nt osa luulet) on kuulatuna mõjukad ja ilusad, kirjapanduna aga kaotavad oma sära.

Muutused visuaalsuse suunas viisid lugemise kiiruse suurenemiseni ja häälega ettelugemisest loobumiseni, sest tekst muutus rutem haaratavaks. Samas ei olnud tegu aga ainult positiivsete kaasnähtustega. Enam ei loetud peamise eesmärgiga omandada tekst võimalikult täiuslikult või kohati isegi pähe õppida. Ehk siis põ hjalik lugeja, nagu kirjeldavad seda Osborne, Steiner ja Derrida, ei ole oma iseloomult skolastilis-akadeemiline. Kui varakeskaegne Benedictuse mungareegel (VI saj) eristas veel kolme lugemistüüpi: lugemine (lectio); läbimõtlemine, meeldejäetu omaette poolihääli kordamine (ruminatio $^{7}$ ja ettelugemine (recitatio) (Hamesse 2003: 106), siis XII sajandil hakkas see ülikoolide esilekerkimisega seoses muutuma. Poolihääli tekstide kohale kummardunud pobisemine ei kuulu olemuslikult mitte skolastilisse, vaid sellele eelnenud ajastusse. See on traditsioon, mida me võime praegu näha veel nt muhameedlaste medresetes ja juutide ješiva-koolides, aga mis kristlikus maailmas on praeguseks hetkeks üsna haruldane nähtus. Kuigi nii ruminatio kui ka recitatio olid XII sajandil ikka veel olulised, suurenes omaette vaikselt ja kiiresti lugemise hulk ning lugemine hakkas üha enam kanduma kloostri lektooriumist ülikoolidesse. Varasema traditsiooni kohaselt võis olla, et mungale laenati välja üks raamat, millega ta tutvus põhjalikult aasta vältel, nüüd aga kujunes vajaduseks, et peale elementaarse õpetuse ja autoriteetide oleksid mungad (ja üliõpilased) võimelised lühikese ajaga kas või pealiskaudselt omandama palju suurema hulga tekste ja infot. Just siin on lugemisteoreetikud näinud kõige suuremat probleemi: raamatute hulga suurenedes ei ole võimalik kõiki neid enam läbi seedida.

Lugemiskiiruse kõrval sai skolastika ajajärgul iseloomulikuks hüüdlause statim invenire 'otsekohe leida! (Vt Rouse, Rouse 1982.) Tulevad kasutusele teemaindeksid, allmärkused ja sisukorrad ning XIII sajandil toimub ka pühakirja struktureerimine nummerdatud lõikudeks, sest akadeemilis-skolastilises ruumis oli Piiblile vaja järjest täpsemini viidata ja kiiremini seal kirjutatut üles leida. Niisiis enam ei peetud loomulikuks mungalikku kommet võtta ette mõningad tekstid ja lugeda need süvenemisega otsast lõpuni läbi, vaid akadeemilist tava, et lugeja haaras teksti ja leidis sellest kiiresti vajalikud kohad, jättes tähelepanuta selle, mis teda parajasti ei huvitanud. Vältimatu on selline indeksite ja viidete tugisüsteem just ajajärgul, mil tekste on väga palju, ja kuna katoliikluses on traditsioon ja Pühakiri võrdväärse tähtsusega, pidid keskaegsed filosoofid ja teoloogid olema tuttavad kogu eelneva mõtlemise ajalooga.

Siinkohal tuleb ka rõhutada, et kuigi autori isik hakkab XII sajandist alates tekstides rohkem silma paistma, ei kujune see siiski skolastilisele tekstile üldiseloomulikuks, vaid viimase tunnuseks on peamiselt distantseeritud ja akadeemiline stiil, mis on teadustekstides nõutav ka tänapäeval. Nii ongi sageli välja toodud, et nt Descartesi „Meditatsioonid” on XVII sajandil ikka veel valitseva skolastilise mõtlemise taustal muuhulgas uudsed ka selle poolest, et ei tsiteeri otsesõnu mitte ühtegi autorit ning tegelevad vaid isiku enese kaemusega. Sellisesse isiklikku kaemusesse suhtus skolastika üldjoontes kahtlevalt ning ka isiklikule kaemusele omast originaalsust peeti skolastikas pigem puuduseks kui vooruseks. Niisugune lähenemine oli valdav hellenismi-

\footnotetext{
${ }^{7}$ Otsetõlkes 'läbimälumine'.
} 
perioodist alates - heaks näiteks sellele on Plotinose (keda traditsiooniliselt peetakse uusplatonismi rajajaks ja antiigi üheks olulisemaks mõtlejaks üldse) enda seisukoht, et kõige kaalukamad kohad tema õpetuses on olemas juba Platonil ning tema tegeleb vaid selle laiendamise ja kommenteerimisega. „Need õpetused ei ole seega uudsed, mingisugused tänapäevased leiutised, vaid juba ammu esitatud” (Plotinos, „Enneades”, V.1.8). Niiviisi nägid nii hellenistlikud kui ka skolastilised mõtlejad oma rolli peamiselt eelnevate autorite tekstide läbilugemisel, töötlemisel ja kommenteerimisel, mitte aga uudsete seisukohtade loomisel ja originaalsel lähenemisel. Eelduseks oli tõdemus, et kõik oluline on juba ammu välja öeldud ja kirja pandud. Vahest kõige paremini võtab seda tüüpi mõtlemise kokku XII sajandi tähelepanek, et me oleme nagu kääbused hiiglaste õlgadel (Stock 1979).

Et hiiglaste õlgadele ronimist hõlbustada, hakati juba hilisantiigis koostama antoloogiaid ja entsüklopeediaid olulisematest filosoofilistest ja loodusteaduslikest seisukohtadest. Sümptomaatiliseks ja ühtlasi eriti populaarseks kujunesid keskajal erinevad florileegiumid ja distinctiones-kogumikud, kuhu oli kokku kogutud lõike, mida sai niiviisi kerge vaevaga omandada, pidamata sealjuures originaaltekste läbi lappamagi. Kuigi sellised excerptiones-kogumikud on teada juba alates VII sajandist, siis populaarseks saavad need alles XII sajandist koos ülikoolide kasvuga (Rauner 1989).

Tehnoloogilistest saavutustest kirjutamiskiiruse suurendamiseks skolastilisel perioodil on olulisel kohal veel nn pecia (poognate) kaupa kopeerimise süsteem. See tähendas otsustavat murrangut võrreldes eelnevate sajanditega, kui raamatute paljundamine toimus valdavalt kloostrites ning turg raamatuhuviliste vähesuse tõttu praktiliselt puudus. Enne vahetasid raamatud omanikke harva ning neid pigem kingiti kui osteti või müüdi. Ülikoolide esilekerkimisega suurenes aga raamatutest huvituvate inimeste arv. Kui antiikja varakeskajal kopeeriti tekste peamiselt diktsiooni teel ning ka varasem kloostritraditsioon eelistas dikteerija ja kopisti koostööd, siis alates XII sajandist kasutatakse üha rohkem visuaalset kopeerimist (niisugusest praktikast annavad tunnistust spetsiifilised vead selle perioodi ümberkirjutustes). Alguses toimus visuaalne kopeerimine nii, et ümberkirjutatav raamat asetati lugemiseks põlvedele, kuid hiljem kopeeriti tekste juba laua kohale monteeritud spetsiaalselt puldilt. Pecia-süsteem täiendas kirjeldatud olukorda veelgi: kopist ei pidanud ümber kirjutama enam tervet raamatut korraga, vaid sai seda teha osade kaupa. Selline muutunud olukord põhjustas XIII sajandil nn stationarius'te tekke. Need ülikoolide juures olevad ettevõtted on kirjeldatavad algeliste kirjastustena: stationarius võttis sisse käsikirja, lasi selle kellelgi ette valmistada (või korrigeeris ise) ning hakkas seda poognate kaupa välja üürima. Pecia-süsteem kiirendas olulisel määral tekstide ümberkirjutamist, sest sai võimalikuks, et ühe teksti kallal töötab korraga suur hulk inimesi.

Kõik kirjeldatud skolastilised praktikad - kiiremini tekste luua, teha need kättesaadavaks võimalikult paljudele - on praegusaegse teadustegevuse juureski levinud. Mõnda aega tagasi ilmus ajakirjas Akadeemia otsingumootoritega seotud lugemismuudatusi puudutav artikkel, mis kirjeldab ka skolastilist olukorda (Carr 2008). Teadusartiklite jaoks andmebaasidest noppeid ja relevantseid lõike välja otsides on oht, et mõistmise nüansseeritus kaob. Samamoodi nagu meie oleme praegusel ajal otsingumootorite meelevallas, olid florileegiumide ja distinctiones-kogumike lugejad nende koostajate meeleval- 
las. Tehti ju lõikude ja sententside valikul alati eelselektsioon mingisugusest suuremast tekstihulgast ning valik peegeldas alati kellegi erihuvisid. Mõnikord juhtus, et selektsioon oli tehtud eesmärgiga vähendada vastuolusid ja siluda keerulisi teoloogilisi probleeme ning oli seega olemuslikult tasandav ja tsensuurist mööda hiiliv. Teinekord püüdis selektsioon näidata vastuolusid seal, kus neid polnud. Tänapäevases akadeemias on artiklite produtseerimise nõue samamoodi loonud olukorra, kus kiiresti ja pealiskaudselt lugedes ning andmebaasidest relevantseid tekstilõike otsides leitakse toetust eelkõige omaenda mõtetele. Teiste autorite tekstijuppidest saab tööriist ja tellingud juba valmismõeldud konstruktsioonidele, tegemist on skolastilise statim invenire ('otsekohe leida, kiiresti valmis saada') mõtlemisega. Niisugune ruttav kirjutamine-lugemine võib luua olukorra, kus kõik kassid on öösel hallid - me ei saa teadagi, mida autorid mõtlesid, ehk mis värvi lõpuks ikkagi on see kass, kes on katusel. Samas aga võib juhtuda, et märksõnaga andmebaasist teksti otsides võib sattuda artikli või tekstilõigu peale, mis suunab su mõtted täiesti uutele radadele või osutub vajalikuks hoopis teises vallas.

See probleem ei olnud keskaegsetele autoritele mõistagi võõras. Kurtsid nad liigse sekundaarkirjanduse kasutamise pärast juba XII sajandil ning õhutasid õpilasi pöörduma kokkuvõtva glossi (ääremärkuse) ja kommentaari juurest originaalide poole (ad originalia), sest miski muu ei suuda autori mõtet paremini edasi anda (Rouse, Rouse 1982: 223). Ometigi jäi nende õhutus praktilistele kaalutlustele alla ning erinevate kogumike, florileegiumide jms populaarsus üha kasvas. On spekuleeritud, et sellisele entusiasmile panid piiri alles XIV sajandi katkuepideemiad, mis, laastates peamiselt linnu, muutsid kirjaoskajate hulga oluliselt väiksemaks. Nii või teisiti - autorite ja allikate endi juurde tagasipöördumine oli teatavas mõttes just see juhtnöör, mida järgides sai alguse reformatsioon XVI sajandil ning mille tulemusena saame rääkida humanismist ja lõpuks ka u u s a j a s t. Paarkümmend aastat pärast seda kui Trithemius kurtis selle üle, et käsitsi kirjutamine on kaduma hakkav suurus, kirjutas Rotterdami Erasmus: „[E]siteks tuleks tagasi pöörduda allikate juurde ( $a d$ fontes), see tähendab kreeklaste ja antiiksete juurde"8 (Erasmus 1528: a5). Selline uue vagaduse (devotio moderna) vaimust kantud liikumine viis lõpuks tagasi meditatsioonide ja isikliku pühendumuse juurde. Seab ju reformatsioon ainukeseks aluseks Pühakirja ja lükkab traditsiooni (ehk siis vahepealsed autorid) põlgusega kõrvale, nagu humanistid lükkasid kõrvale keskaegse filosoofia ja teoloogia. Selliselt vähendati oluliselt nn kohustusliku kirjanduse hulka.

Kokkuvõtlikult - nii kirjutamine kui ka lugemine on pidevas muutuses ning ikka ja jälle kerkivad uuel moel üles juba ammu aega tagasi tuttavaks saanud probleemid. Need ei ole seega uudsed, mingisugused tänapäevastest leiutistest tulenevad mured, vaid juba ammu esitatud. Friedrich Nietzsche kurtis juba rohkem kui 100 aastat enne Hettchet ja e-raamatuid, et mitte keegi ei oska enam lugeda ega tõeliselt tekste väärtustada (Allen 1991: 86). Tehnoloogiate muutus küll kombineerib ja loob juurde võimalusi teksti poole pöörduda ja mõistagi katab samas teatava hulga võimalusi kinni, kuid täielike muutuste esilekutsumiseks jääb ainult tehnikast väheseks. Õhtumaa allakäigu meeleolude asemel näib mõttekam pöörata lihtsalt senisest rohkem tähelepanu sellele, kuidas ja mida me loeme. Lugeda on ju aasta-aastalt üha

\footnotetext{
${ }^{8}$ Sed in primis ad fontes ipsos properandum, id est graecos et antiquos.
} 
rohkem ja rohkem ning üha keerulisemaks muutub küsimus, mida siis ikkagi peaks kätte võtma. Kui midagi kaduma hakkab, siis on see alus, hiiglane, kelle õlgadele toetuda. Just selle tõttu püüab iga tekst saada iseseisvaks, originaalseks või äärmisel juhul triloogiaks või veel pikemaks sarjaks. Millised aga on need neli raamatut, mis peaksid kindlasti kõigil kodus olemas olema ning mida peaks põhjalikult läbi mäluma ja seedima? Enam pole mitte kellelgi autoriteeti seda kehtestada, sest mitte keegi ei tea seda. Kuna puudub ühtne ja ühendav alus, siis peitub siin teatavas mõttes oht intellektuaalsele järjepidevusele ja tulemuseks on paratamatu kultuuriline getostumine. Erinevad grupid toetuvad erinevatele tekstidele ning selliselt isoleerivad end teistest gruppidest hermeetilis-esoteerilise mõistmatuse seinaga.

\section{Kirjandus}

Alle n, James Sloan 1991. The existential reader: Or reading, rumination, and the classics. - Sewanee Review, kd 99, nr 1, lk 86-100.

A ug u stinus, Aurelius 2007. Pihtimused (= Confessiones). Tlk Ilmar Vene. 2. tr. Tallinn: Logos.

B e r g k, Johann Adam 1799. Die Kunst, Bücher zu lesen: Nebst Bemerkungen über Schriften und Schriftsteller. Jena: Hempel.

C a r r, Nicholas 2008. Kas Google muudab meid lolliks. Tlk Tanel Toobik. - Akadeemia, nr 12, lk 2708-2719.

Eisenstein, Elizabeth L. 1980. The Printing Press as an Agent of Change: Communications and Cultural Transformations in Early Modern Europe, I-II. Cambridge: Cambridge University Press.

E r a s m u s, Desiderius 1528. De ratione studii, ac legendi, interpretandique autores, Libellus aureus. Lugdunum [Lyon]: Gryphius.

Fr a s c a-S p a d a, Marina, J a r d i n e, Nicholas 2000. Books and the Sciences in History. Cambridge: Cambridge University Press.

H a m e s s e, Jacqueline 2003. The scholastic model of reading. - A History of Reading in the West. Toim Guglielmo Cavallo ja Roger Chartier. Oxford: Polity.

H e t t c h e, Thomas 2013. Papüürused. Tlk Kalle Hein. - Akadeemia, nr 5, lk 809_ 823.

Hexter, Ralph, Town send, David 2012. The Oxford Handbook of Medieval Latin Literature. Oxford: Oxford University Press.

M o r r i s, Colin 2004. The Discovery of the Individual, 1050-1200. (Medieval Academy Reprints for Teaching 19.) Toronto-Buffalo-London: University of Toronto Press.

R a u n e r, E. 1989. Florilegien, 1. Mittellateinische Literatur. - Lexikon des Mittelalters. IV. Stuttgart: Metzler, vg 566-569.

R o u s e, Richard H., R o u s e, Mary A. 1982. Statim invenire: Schools, preachers, and new attitudes to the page. - Renaissance and Renewal in the Twelfth Century. Toim Rober Louis Benson, Giles Constable ja Carol Dana Lanham. Cambridge-Mass: Harvard University Press, lk 201-225.

S a e n g e r, Paul 1997. Space Between Words: The Origin of Silent Reading. Stanford: Stanford University Press.

S a e $\mathrm{n}$ g e r, Paul 2003. Reading in the later Middle Ages. - A History of Reading in the West. Toim Guglielmo Cavallo, Roger Chartier. Oxford: Polity, lk 120-148. 
S t e i n e r, George 2008. Valik esseid. - Loomingu Raamatukogu, nr 33-34. Tallinn: SA Kultuurileht.

S t o c k, Brian 1979. Antiqui and Moderni as 'giants' and 'dwarfs': A reflection of popular culture? - Modern Philology, nr 76 (4), lk 370-374.

\section{Of gnomes and giants}

Keywords: history of reading, history of books, history of writing

Different material aspects of the book have observable influence on reading practices and the resulting reading customs reflect on the intellectual activities and priorities of different periods. In antiquity scrolls and continuous writing resulted in social and listener-orientated reading practices, while the use of scribes contributed to the somewhat detached character of the text. The spread of the codex format of the book and especially of word-separated writing, which appeared in the medieval period, gave rise to a silent reading tradition, which was more of a meditative character. Silent reading enables the reader to absorb text more quickly and in university context this develops into scholastic reading, which may even be uninterested in reading whole texts from beginning to end but, instead, tries to find relevant portions of the texts quickly and effectively. This, in turn, gives rise to indexes and other elements that aim to organize the page and help guide the readers eye. Due to the difficulty of producing manual copies of texts the scholastic environment caused a proliferation of florilegia and different excerpt-collections. Only after the invention of the printing press it was possible for students to follow the appeal to turn back to originals and sources. Still, the mass of the available books was not incomprehensibly big and there were certain texts (especially by ancient authors) that every student had ruminated and thus knew thoroughly. Technological advances in the printing technology of the following centuries and especially the advance of computers and the internet in the previous century have made it possible to produce unprecedented volumes of texts. Such processes have not resulted in the disappearance of reading (which is the concern of some authors) but instead an uncertainty as to which books should be read thoroughly. The resulting groundlessness could create a kind of perpetual culture gap or discontinuity of culture.

This is why every text strives to become independent, original, or at least a trilogy if not a still longer series (Hettche 2013: 811). Yet, what are the four books everybody should have at home to be seriously ruminated? There is no authority left to impose them, because nobody knows what they are. In a way this lack of a unified and uniting basis jeopardizes intellectual consistency, thus inevitably resulting in cultural ghettoisation. Different groups of people relying on different texts are isolating themselves from the others by a wall of hermetic esoteric incomprehensibility.

Meelis Friedenthal (b. 1973), doctor theologiae, senior research fellow at the University of Tartu Library, meelis.friedenthal@ut.ee 